\title{
Illegally additives determination by thin layer chromatography
}

\author{
Xin LIANG $^{1}$, Jie ZHANG ${ }^{1}$, Ting Ting LIU ${ }^{1}$, Li LI ${ }^{1 \text {,a }}$ \\ ${ }^{1}$ Department of Pharmaceutics, Qiqihar Medical University, Qiqihar, China
}

\begin{abstract}
To find out a simple TLC method, which could identify m-phenyenediamine and ophenylenediamine in several colors of oxidation hair coloring products simultaneously. The colors includes black, yellow, brown and red. A small amount of the sample was placed on a silica gel $\mathrm{GF}_{254}$ plate by sample applicator and run using a solvent containing ethyl acetate- butanol -water (37.5:37.5:25 vol). This study established TLC conditions which could let phenylenediamines better separaed and be detected in oxidation hair coloring products simultaneously.
\end{abstract}

\section{Introduction}

Currently phenylenediamines had been detected in many hair coloring products, the detect method has been establish ever before. But there is not any study to expode phenylenediamines may be detected in what kind of color. It is well reported that these dye products are of health concern due to risks of allergic dermatitis, nephrotoxic and carcinogenic effects ${ }^{[1-5]}$. In Chinese hygienic standard for cosmetics, OPD, MPD are forbidden to be added $^{[6]}$.

Thin layer chromatography (TLC) is a widely employed laboratory technique and is similar to paper chromatography. However, instead of using a stationary phase of paper, it involves a stationary phase of a thin layer of adsorbent like silica gel, alumina, or cellulose on a flat, inert substrate. Compared to paper, it has the advantage of faster runs, better separations, and the choice between different adsorbents. For even better resolution and to allow for quantification, highperformance TLC can be used. An older popular use had been to differentiate chromosomes by observing distance in gel (separation of was a separate step). ${ }^{[7]}$

Thin-layer chromatography can be used to monitor the progress of a reaction, identify compounds present in a given mixture, and determine the purity of a substance. Specific examples of these applications include: analyzing ceramides and fatty acids, detection of pesticides or insecticides in food and water, analyzing the dye composition of fibers in forensics, assaying the radiochemical purity of radiopharmaceuticals, or identification of medicinal plants and their constituents. ${ }^{[8]}$

A number of enhancements can be made to the original method to automate the different steps, to increase the resolution achieved with TLC and to allow

\footnotetext{
${ }^{a}$ Corresponding author:836009379@qq.com

Project supported by Qiqihar Medical University (Grant No. QY2016Z-22)
}

more accurate quantitative analysis. This method is referred to as HPTLC, or "high-performance TLC".

The norms for determining oxidation type dye in hair dye is high performance liquid chromatography. But the new methods are more convenient and fast.

\section{Experiment}

\subsection{Materials}

N-butanol was purchased from Tianjin tianli Chemical Reagent Co., Ltd. Ethyl acetate and anhydrous ethanol was purchased from Tianjin fuchen Chemical Reagent Factory. All reagents were analytical purity. mphenyenediamine(MPD), o-phenylenediamine(OPD) and $\mathrm{p}$-Phenylenediamine(PPD) from Tianjin guangfu institute of fine chemicals were used as reference substances. Oxidation hair coloring products was purchased from the same company, but different in colors.

\section{Method}

\subsection{Reference solutions}

Weigh about $50 \mathrm{mg}$ of the reference substance accurately in a standard $10 \mathrm{ml}$ flask. Add $5 \mathrm{ml}$ of $96 \%$ ethanol and $250 \mathrm{mg}$ of ascorbic acid. Make the solution alkaline by addition of the ammonia solution to give an apparent $\mathrm{pH}$ of 10 (test with indicator paper). Make up to $10 \mathrm{ml}$ with $96 \%$ ethanol and $\mathrm{mix}^{[9]}$.

\subsection{Treatment of test samples}

Discard the first 2 or $3 \mathrm{~cm}$ of cream extruded from the tube. Put the following into a centrifuge tube previously 
flushed out: $300 \mathrm{mg}$ ascorbic acid with $3 \mathrm{~g}$ cream. Add $25 \%$ ammonia drop-wise until the $\mathrm{pH}$ is 10 . Make up to $10 \mathrm{ml}$ with $96 \%$ ethanol. stopper and then centrifuge at 4 $000 \mathrm{r} / \mathrm{min}$. For 10 minutes.

\subsection{Developing solvents}

In the EU's governing cosmetic products rules, benzene - 2-butanol - water $(50: 25: 25)$ was used in identification of certain oxidation colorants in hair dyes.

Considering of the toxicity of benzene and the non applicability to quick identification, the developing solvents were replaced and optimized ${ }^{[10]}$. According to Zhang Jingbao's classification of common solvents ${ }^{[11]}$, benzene as electron acceptor, then according to the boiling point, viscosity, volatile, toxic, cost and other factors, preliminary determination of ethyl acetate as a substitute. Because the restrictions of the actual reagent used, using n-butanol instead of butyl alcohol. Similarly, ethyl acetate substitute for benzene. Change the proportion of developing solvents to determine the best ratio of percentage by graphic method, combined with the developing time, select the best developing solvent system.

\subsection{System suitability test}

\subsubsection{Detection sensitivity}

Preparation of $5.0 \mathrm{mg} / \mathrm{mL}$ reference solutions, and were diluted to $0.5 \mathrm{mg} / \mathrm{mL}, 1.0 \mathrm{mg} / \mathrm{mL}, 2.0 \mathrm{mg} / \mathrm{mL}, 4.0 \mathrm{mg} / \mathrm{mL}$. Then apply at points 1,2 and 3 respectively $2 \mu \mathrm{L}$, using the best developing solvent system to run .View in the UV lamp 254nm.olvent system.

\subsubsection{Rf value}

Apply $2 \mu \mathrm{L}$ of each of the reference solutions, develop, written down the distance of baseline to spread advanced. View in the UV light at the wavelength of $254 \mathrm{~nm}$, draw the main spot of OPD, MPD, PPD, write down the baseline to the spot center distance.

\subsubsection{Resolution}

Pipette with an equal amount of OPD, MPD, PPD reference solution mixed. Apply $2 \mu \mathrm{L}$ at first point and apply $2 \mu \mathrm{L}$ reference solution at following points, develop, write down the baseline to spread advanced distance. Under the $254 \mathrm{~nm}$ UV lamp examination, draw the main spot location, radius of OPD, MPD, PPD. Writing down the distance of baseline to spot center, and calculating the separating degree $\mathrm{R}$.

\subsubsection{Sample quantity choice}

Using the supernatant, apply at points 1, 2, 3 and 4 respectively $2 \mu \mathrm{L}, 4 \mu \mathrm{L}, 6 \mu \mathrm{L}, 8 \mu \mathrm{L}$ of the test solution samples. Using the best developing solvent system.
Observation under the UV lamp 254nm.

\subsubsection{Identification}

Compare the $\mathrm{R}_{\mathrm{f}}$ value and the colour obtained from the sample with those of the reference substances chromatographed.

\section{Results}

\subsection{Optimization of developing solvents}

Change the ratio of ethyl acetate and n-butanol. The $R_{f}$ values and development time of OPD, MPD, PPD as shown in table 1 .

Table 1. Different ratio of TLC chromatogram development using ethyl acetate - n-butanol - water

\begin{tabular}{cccc}
\hline \multicolumn{4}{c}{ Developing solvents $(\%, \mathbf{v} / \mathbf{v})$} \\
groups & ethyl acetate & n-butanol & water \\
\hline 1 & 60.0 & 15.0 & 25.0 \\
3 & 45.0 & 35.0 & 25.0 \\
4 & 37.5 & 37.5 & 25.0 \\
5 & 30.0 & 45.0 & 25.0 \\
\hline
\end{tabular}

When the percentage of the ethyl acetate is $37.5 \%$, namely, ethyl acetate: n-butanol: water $=37.5: 37.5: 25$, adjacent spots maximum separation degree, the separation of the components that get ideal. (Table.2)

Table 2. $\mathrm{R}_{\mathrm{f}}$ values of TLC chromatogram development using ethyl acetate - n-butanol - water

\begin{tabular}{cccc}
\hline groups & $\mathrm{R}_{\mathrm{f}}$ OPD & $\begin{array}{r}\mathbf{R}_{\mathrm{f}} \text { values } \\
\mathrm{R}_{\mathrm{f}} \text { MPD }\end{array}$ & $\mathrm{R}_{\mathrm{f}}$ PPD \\
\hline 1 & 0.83 & 0.82 & 0.73 \\
2 & 0.82 & 0.71 & 0.72 \\
3 & 0.85 & 0.78 & 0.73 \\
4 & 0.78 & 0.74 & 0.67 \\
5 & 0.88 & 0.78 & 0.77 \\
\hline
\end{tabular}

\subsection{Detection sensitivity}

$0.5 \mathrm{mg} / \mathrm{mL}, 1.0 \mathrm{mg} / \mathrm{mL}, 2.0 \mathrm{mg} / \mathrm{mL}, 4.0 \mathrm{mg} / \mathrm{mL}$ of reference solutions were detected. Apply at points 1,2 and 3 respectively $2 \mu \mathrm{L}$, using the best developing solvent system to run. View in the UV lamp $254 \mathrm{~nm}$.olvent system. 
The concentration that produced the spot with the least observable spot was noted. The sensitivity of ophenylendiamine is $0.5 \mathrm{mg} / \mathrm{mL}$. The sensitivity of $\mathrm{m}-$ phenylendiamine is $0.5 \mathrm{mg} / \mathrm{mL}$. The sensitivity of $\mathrm{p}-$ phenylendiamine is $0.5 \mathrm{mg} / \mathrm{mL}$ (Figure 1 ). a)

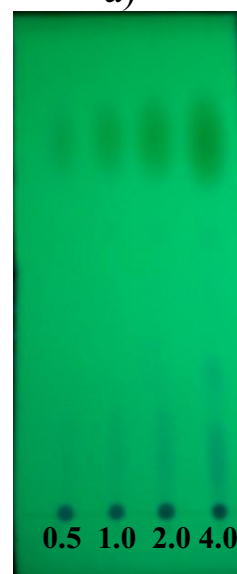

b)

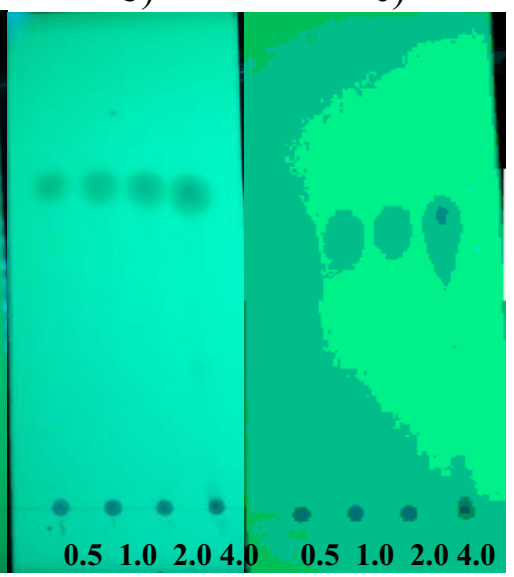

Figure 1. Uv spectrophotometry showing the observable spots of different concentrations. (a) OPD $(0.5-4.0 \mathrm{mg} / \mathrm{ml}$ applied), (b) MPD (0.5 - $4.0 \mathrm{mg} / \mathrm{ml}$ applied), and PPD $(0.5-4.0 \mathrm{mg} / \mathrm{ml}$ applied). The assay was carried a silica gel $\mathrm{GF}_{254}$ plate which had been eluted with ethyl acetate- butanol -water (37.5:37.5:25 vol).

\section{3 $R_{f}$ values}

$2 \mu \mathrm{L}$ of each of the reference solutions was applied, developed, written down the distance of baseline to spread advanced. View in the UV light at the wavelength of $254 \mathrm{~nm}$, draw the main spot of OPD, MPD, PPD, write down the baseline to the spot center distance. Measure the corresponding distances and calculate $R_{f}$ values(Table 2).

\subsection{Resolution}

Under the $254 \mathrm{~nm}$ UV lamp examination, draw the main spot location, radius of OPD, MPD, PPD. Writing down the distance of baseline to spot center, and calculating the separating degree.

Calculate the degree of separation between adjacent spots, the resolution of $\mathrm{o}$-phenylendiamine and $\mathrm{m}$ phenylenediamine is 1.7 , the resolution of $\mathrm{m}$ phenylenediamine and p-phenylenediamine is 1.2.

The resolution are both greater than 1 , so been eluted with ethyl acetate- butanol -water (37.5:37.5:25), the separating degree of spots is good (Figure2).

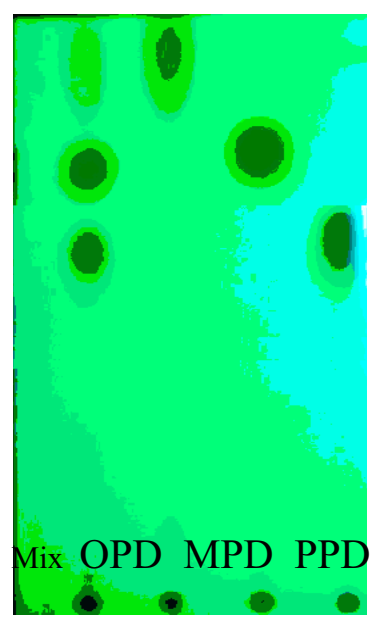

Figure 2. Uv spectrophotometry showing the observable spots of the resolution of three reference substance. The assay was carried a silica gel GF254 plate which had been eluted with ethyl acetate- butanol -water (37.5:37.5:25 vol).

\subsection{Sample quantity choice}

$2 \mu \mathrm{L}, 4 \mu \mathrm{L}, 6 \mu \mathrm{L}, 8 \mu \mathrm{L}$ of the test solution samples was applied. The assay was carried a silica gel GF254 plate which had been eluted with ethyl acetate- butanol -water (37.5:37.5:25 vol). Observation under the UV lamp $254 \mathrm{~nm}$.

Four colors of commercial hair dyes, $6 \mu \mathrm{L}$ spots were clear, separation effect is good, is the best point sample.

\subsection{Identification}

The $\mathrm{R}_{\mathrm{f}}$ value was compared with the colour obtained from the sample with those of the reference substances chromatographed.

Four kinds color of commercial hair dyes failed to detect the illegal additives OPD, MPD. But the yellow dye hair cream Color was detected with PPD(Figure3).

a)

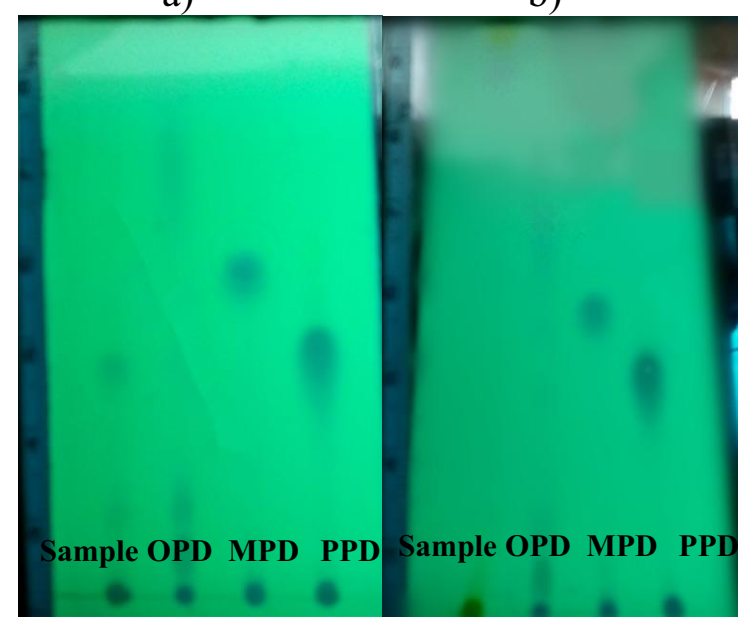

c) d) 


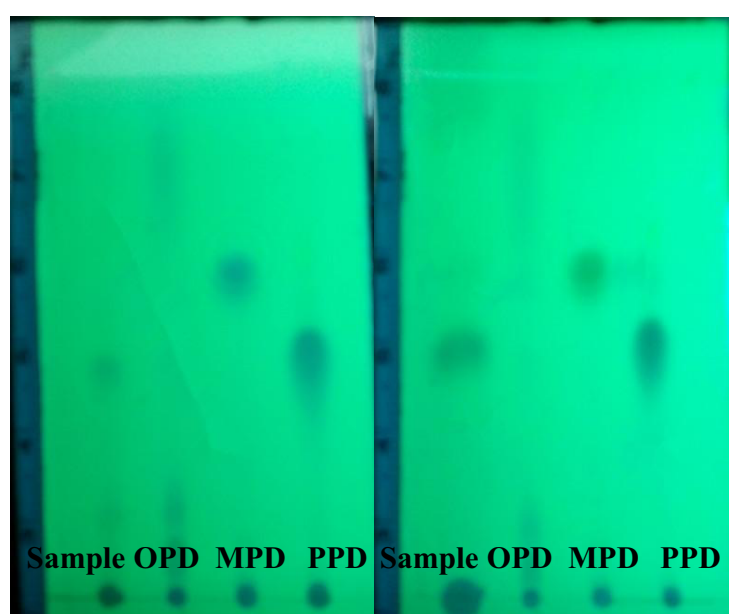

Figure 3 UV spectrophotometry showing the observable spots of four commercial hair dyes.(a) red dye hair cream, (b) black dye hair cream, (c) brown dye hair cream, (d) yellow dye hair cream. The assay was carried a silica gel $\mathrm{GF}_{254}$ plate which had been eluted with ethyl acetate- butanol -water (37.5:37.5:25 vol).

\section{Discussion}

The test choice was a non-toxic ethyl acetate - nbutanol - water (2:1:1) system, but the separation effect is not so well, and too slow, the Rf Value was not ideal. After elevate the ratio of n-butanol, finally determine to take ethyl acetate- butanol -water (37.5:37.5:25 vol) as the developing solvent. The separation effect was good, OPD, MPD, PPD can be well separated, the spot is round,tailing phenomena was not obvious.

TLC method is simple, good reproducibility, high sensitivity, can be used as an identification method of check illegal additives in the hair dye. By thin layer chromatography (TLC) to identify the hair dye illegally added ingredients, should have the standard samples and test samples at the same time for thin layer chromatographic analysis. After developing, the spots of standard and test samples have same shape, Rf value and color, can be a preliminary conclusion is that the same compounds. There was no illegal ingredient added in the four kinds of color commercial permanent colorants, But the yellow dye hair cream Color was detected with PPD.

The results showing that yellow color commercial permanent colorants tends to be added with illegal ingredients, but there are still no evidences indicating that yellow color commercial permanent colorants contain OPD,MPD.

\section{Acknowledgement}

This paper is supported by Qiqihar Medical University (Grant No. QY2016Z-22).

\section{References}

1. B.Desmedt, P. Courselle, J.O. De Beer, V. Rogiers, E.Deconinck, K. De Paepe. Illegal cosmetics on the EU market: a threat for human health? Archives of Toxicology Volume 88, Issue 9, 1765-1766 (2014) 2.Desmedt B, Rogiers V, Courselle P, De Beer J, De Paepe K, Deconinck E. Development and validation of a fast chromatographic method for screening and quantification of legal and illegal skin whitening agents. JPharm Biomed Anal 83:82-88(2013)

3.Desmedt B, Van Hoeck E, Rogiers V, Courselle P, De Beer J, De Paepe K, Deconinck E. Characterization of suspected illegal skin whitening cosmetics. J Pharm Biomed Anal 90:85-91(2014)

4.Karamagi C, Owino E, Katabira E. Hydroquinone neuropathy following use of skin bleaching creams:case report. East Afr Med J 78(4):223-224. (2001) 5.Olumide YM, Akinkugbe AO, Altraide D, Mohammed T, Ahamefule N, Ayanlowo S, Onyekonwu C, Essen N. Complications of chronic use of skin lightening cosmetics. Int J Dermatol 47(4):344-353(2008) 6. The ministry of health of the People's Republic of China. Hygienic Standard for Cosmetics. (Beijing: military medical science press, 2007)

7.Harry W. Lewis and Christopher J. Moody. Experimental Organic Chemistry: Principles and Practice (Illustrated ed.). WileyBlackwell. 159-173(1989) 8.A.I. Vogel, A.R. Tatchell, B.S. Furnis, A.J. Hannaford, and P.W.G. Smith. Vogel's Textbook of Practical Organic Chemistry (5th ed.).

9.The rules governing cosmetic products in the European Union Cosmetic products Methods of analysis. European Commission. Enterprise Directorate-General Pharmaceuticals and cosmetics, 35-41(1999).

10.Liu Ziyao, Sun Shuwen, Xiao Haiying, Leng YiPing. TLC is analysed in the choice of new agents and alternative method. Journal of China modern distance education of Chinese medicine. 9 (10): 222-223(2011) 11.Zhang Jingbao, Ban Yundong. Commonly used solvents of FUZZY clustering analysis. Journal of chromatography. 7 (5): 256-261(1989). 